\title{
10,000 Black Men named George, un téléfilm sur une grève d'employés des wagons-lits dans l'entre- deux-guerres
}

10,000 Black men named George, a TV movie about a Pullman's porters strike in the 1930

Keith A. Mann

\section{OpenEdition \\ Journals}

Édition électronique

URL : https://journals.openedition.org/rhcf/163

DOI : 10.4000/rhcf.163

Éditeur

Rails \& histoire

Édition imprimée

Date de publication : 1 décembre 2007

Pagination : 331-334

ISSN : 0996-9403

Référence électronique

Keith A. Mann, « 10,000 Black Men named George, un téléfilm sur une grève d'employés des wagons-lits dans l'entre-deux-guerres », Revue d'histoire des chemins de fer [En ligne], 36-37 | 2007, mis en ligne le 10 mai 2011, consulté le 22 avril 2022. URL : http://journals.openedition.org/rhcf/163 ; DOI : https:// doi.org/10.4000/rhcf.163 


\title{
10,000 Black Men named George, un téléfilm sur une grève d'employés des wagons-lits dans I'entre-deux-guerres
}

\author{
Keith A. Mann \\ Assistant Professor, Department of History, Cardinal Stritch \\ University Milkwaukee
}

Les années 1920 et 1930 furent, aux États-Unis, celles de l'âge d'or du transport ferroviaire. Depuis les années 1880, la société Pullman y fabriquait des voitures à voyageurs haut de gamme et les louait aux grandes compagnies de chemin de fer. D'une rare beauté et très confortables, ses parlor cars étaient équipés de beaux tapis et de lambris d'essences rares, produits par des artisans talentueux. Pour servir les voyageurs, Pullman avait formé un corps de serveurs/valets en livrée blanche et toujours empressés, les « porteurs ». Habiles et attentifs dans leur service, ils étaient aussi très gentils, toujours souriants. Pullman avait lancé une campagne de publicité centrée sur les miles of smiles (tonnes de sourires) que les passagers trouveraient à bord de ses trains. Ils n'avaient pas à apprendre le nom de chacun des porteurs, puisque tous étaient nommés George (en hommage à George Pullman, fondateur de la société)! Les porteurs avaient également en commun d'être exclusivement des hommes et d'être tous noirs. 10000 Black Men named George raconte les luttes émancipatrices de ces travailleurs opprimés, tant sur le plan des rapports salariaux que des rapports Blancs/Noirs, dans la très raciste société états-unienne des années 1920 et 1930. C’est cette double oppression de race et de classe qui donne à l'histoire des porteurs sa dimension originale.

Ce téléfilm, produit par la société Shontime Premium, a été diffusé sur une chaîne privée pour la première fois le 24 février 2002, et est désormais disponible sur DVD. Le metteur en scène, Robert Townsend, a produit onze autres films depuis 1987 et joué dix-sept rôles, parfois dans ses propres œuvres. Né en 1957, Townsend milite pour changer l'image des Noirs - toujours trop souvent négative - dans le cinéma états-unien. La performance d'André Braugher qui joue Asa Philip Randolph, chef du syndicat indépendant des porteurs, reflète l'intelligence et l'intensité de l'engagement de Randolph. Ses camarades à la direction du syndicat sont joués par Mario van Peebles, Brock Peters et Charles Dutton, des acteurs noirs américains connus. 
Le film s'ouvre sur de beaux clichés de trains de voyageurs avec des locomotives à vapeur en tête, ce qui fera plaisir à tout amateur du rail. Puis les premières scènes montrent la double exploitation des porteurs, le système des pourboires utilisé par des clients blancs pour s'amuser en les humiliant. Un porteur surprend une passagère blanche en train de plier des draps et une couverture de Pullman dans sa valise; pour sa peine, le porteur, qui est responsable de toute perte de matériel, est accusé par la dame d'avoir mis la couverture dans sa valise. À ce moment-là, un grave accident survient, une collision avec un autre train qui n'est pas sur la bonne voie. Dans le crash, le porteur est brûlé vif par la vapeur qui s'échappe des tuyaux cassés dans l'accident. Il meurt peu après de ses blessures. La direction de la société Pullman en fut navrée. Une voiture fut re-baptisée l'E.J. Daniels en hommage au porteur décédé. Mais la pension accordée par la société était minable (18 dollars par mois), bien insuffisante pour assurer le bien-être de sa famille. Une délégation de la direction du syndicat impulsé par la compagnie demanda alors une augmentation. Pas question! La politique sociale de Pullman ne le permettait pas. Le rôle de ce syndicat-maison, expliquait la direction, consistait à soutenir la politique de la société, non à la faire changer. Le décor de la lutte acharnée qui se déroula entre Pullman et les porteurs pendant des années est ainsi planté.

En 1925, quelques porteurs se mettent en contact avec l'éditeur new-yorkais d'un obscur journal socialiste noir américain, Asa Phillip Randolph, afin de créer un syndicat indépendant. On est en plein boom économique mais les salaires des porteurs stagnent, les humiliations se multiplient. Pullman est farouchement anti-syndical et son syndicatmaison vante les avantages dont bénéficie un employé de Pullman. Randolph, quant à lui, est connu pour ses efforts d'organisation de syndicats de travailleurs noirs, bien qu'ils aient tous échoué. Le Brotherhood of Sleeping Car Porters est né ; son slogan est : Fight or Be Slave. Le mouvement noir américain est, au moment où se déroule le film, en pleine ébullition. La vieille stratégie d'accommodation prônée par une génération antérieure, autour de Booker T. Washington, est contestée. Washington conseillait aux Noirs de modifier leurs demandes pour obtenir l'égalité des droits dans une Amérique ségréguée et raciste. En agissant comme des citoyens patriotes et loyaux à l'égard des Blancs, les Noirs finiraient par obtenir l'égalité au fil du temps. En attendant, ils devaient se doter de compétences artisanales afin de devenir ouvriers qualifiés ou même artisans indépendants. Le sociologue et militant pour les droits civiques W.E.B. Dubois prônait quant à lui une stratégie très différente. Le racisme est la question du vingtième siècle, dit-il. Et c'est un problème 
des Blancs, pas des Noirs. Très influencé par le marxisme, Dubois prendra plus tard sa carte du parti communiste des USA. Tandis que Dubois considère la petite frange de Noirs privilégiée (le talented tenth ou « $10 \%$ doué ») comme avant-garde de la lutte anti-raciste, Randolph, qui soutenait la Révolution russe en 1917 et qui sera plusieurs années à la direction du parti socialiste, estime plutôt que ce rôle d'avant-garde de la lutte doit être joué par les masses noires prolétaires. C’est aussi à cette époque que Marcus Garvey arrive à New York, venant des Caraibes. Il propose une autre stratégie pour la libération des Noirs. Les Noirs n'obtiendront jamais l'égalité aux États-Unis, explique-t-il. La solution est donc d'émigrer, de "retourner », dit Garvey, en Afrique.

Dans les années 1920 et 1930, une très importante migration des Noirs du Sud vers les grandes villes industrielles commence. Des métayers et travailleurs agricoles voient leurs situations disparaitre avec la destruction du coton par les booweavils, insectes parasites. Dans le même temps, l'industrie de l'automobile et la sidérurgie sont en plein essor. Attirés par des emplois relativement bien payés, les nouveaux arrivants sont très majoritairement prolétaires. Mais le mouvement syndical est largement rétrograde en ce qui concerne les femmes, les Noirs et autres non-whites. Cet isolement du grand mouvement syndical et de ses ressources représente un grand obstacle pour Randolph et les porteurs. Le film traite d'une visite effectuée par Randolph à William Green, dirigeant de la centrale syndicale American Federation of Labor (AFL), à laquelle les porteurs demandent d'adhérer. Green les encourage dans leur lutte mais argue du racisme au sein du mouvement syndical qui, à cette époque, se défend de militer publiquement en leur faveur. Se succèdent alors des licenciements, des brimades, des passages à tabac et d'autres tentatives pour empêcher les activités du syndicat auquel le rapport de force est très défavorable. À chacune de ses manifestations, la direction Pullman se livre à une chasse aux sorcières. Ce n'est qu'en 1935 que L'AFL admet le Brotherhood dans ses rangs. Cette même année, le National Mediation Board, établi à la suite de la loi dite Railway Labor Act, organise un vote qui a pour objet la reconnaissance officielle du syndicat. Les « oui » l'emportent et le syndicat a, désormais, une existence officielle. En 1937, après douze années de lutte, Pullman cède en reconnaissant le syndicat et en signant des conventions collectives. Le Brotherhood of Sleeping Car Porters n'est pas le seul syndicat états-unien à enregistrer une telle victoire en 1937. Des grèves sur les tas d'OS et de travailleurs qualifiés dans les grandes usines, mais aussi dans les magasins, transports et autres secteurs sont souvent victorieuses. Ces mouvements inspirent des lois permettant aux syndicats de s'implanter 
sur les lieux de travail. Pour cela, le Wagner Act met en place un appareil juridique qui précise le déroulement des referendums sur l'existence d'un syndicat. C'est à ce moment qu'est créée une instance, le National Labor Relations Board, sorte de cour d'appel pour les conflits sociaux et les litiges dans le travail.

Le film traite aussi des façons diverses dont la société Pullman exerce des pressions sur des porteurs individuels. Parmi eux, certains trouvent, une fois engagés dans les luttes collectives, des forces extraordinaires, deviennent de vrais leaders prolétaires. D’autres prennent ouvertement ou clandestinement le parti du patron, tel ce porteur âgé qui joue le mouchard. Démasqué, il explique sa loyauté envers Pullman et les raisons de ses agissements : né esclave, jeune chômeur au moment de son embauche, il se trouvait sans perspective au moment de son émancipation à la fin de la guerre civile. Le film se termine avec la reconnaissance du syndicat par Pullman en 1937. Randolph devint ensuite un leader de la lutte pour les droits civiques et demanda en 1941 la fin de la ségrégation raciale dans les usines fabriquant du matériel de guerre, menaçant pour cela le gouvernement d'une manifestation à Washington. Craignant la réaction d'une opinion internationale en pleine guerre pour la " démocratie », le président céda. Ce fut une belle victoire pour les Noirs américains et les forces progressistes. Randolph et d'autres leaders du Brotherhood jouèrent un grand rôle dans le mouvement des droits civiques dans les années 1960. Quant au Brotherhood, il fut la victime du déclin des voyages ferroviaires aux États-Unis. De 15000 dans les années 1940, ses adhérents n'étaient plus que 3000 dans les années 1970. En 1979, il fusionna avec un autre syndicat ferroviaire, le BRAC (Brotherhood of Railway and Airline Clerks, aujourd'hui Transportation Communications International Union).

Les porteurs n'existent plus, mais les luttes des travailleurs qui sont opprimés pour leur race, appartenance ethnique ou comme immigrés ont réapparu au début du vingt et unième siècle. Des luttes comme celles des concierges de Los Angeles donnent une certaine actualité à l'histoire racontée par 10,000 Black Men Named George. 